\title{
What's new in pontocerebellar hypoplasia? An update on genes and subtypes
}

\author{
Tessa van Dijk ${ }^{1,2}$, Frank Baas ${ }^{2}$, Peter G. Barth ${ }^{3}$ and Bwee Tien Poll-The ${ }^{3^{*}}$ (ID
}

\begin{abstract}
Background: Pontocerebellar hypoplasia (PCH) describes a rare, heterogeneous group of neurodegenerative disorders mainly with a prenatal onset. Patients have severe hypoplasia or atrophy of cerebellum and pons, with variable involvement of supratentorial structures, motor and cognitive impairments. Based on distinct clinical features and genetic causes, current classification comprises 11 types of $\mathrm{PCH}$.

Main text: In this review we describe the clinical, neuroradiological and genetic characteristics of the different $\mathrm{PCH}$ subtypes, summarize the differential diagnosis and reflect on potential disease mechanisms in $\mathrm{PCH}$. Seventeen PCH-related genes are now listed in the OMIM database, most of them have a function in RNA processing or translation. It is unknown why defects in these apparently ubiquitous processes result in a brain-specific phenotype.

Conclusions: Many new PCH related genes and phenotypes have been described due to the appliance of next generation sequencing techniques. By including such a broad range of phenotypes, including non-degenerative and postnatal onset disorders, the current classification gives rise to confusion. Despite the discovery of new pathways involved in $\mathrm{PCH}$, treatment is still symptomatic. However, correct diagnosis of $\mathrm{PCH}$ is important to provide suitable care and counseling regarding prognosis, and offer appropriate (prenatal) genetic testing to families.
\end{abstract}

Keywords: Pontocerebellar hypoplasia, Pediatric neurology, Genetics

\section{Background}

Pontocerebellar Hypoplasia ( $\mathrm{PCH})$ was originally described as a heterogeneous group of prenatal onset neurodegenerative disorders, mainly but not exclusively affecting cerebellum and pons. The first report on PCH dates from 1917 [1]. Two reports that followed used the term 'hypoplasia ponto- neocerebellaris' to indicate the relative sparing of the cerebellar vermis compared to the cerebellar hemispheres $[2,3]$. In 1928, the clinical characteristics of a patient with $\mathrm{PCH}$ were for the first time described by Krause [4]. He described a 16 months old, atrophic child with swallowing impairment, spasticity and jerky movements of the limbs; in retrospect this description and neuropathological profile fits $\mathrm{PCH} 2$. In 1961 the first patient with $\mathrm{PCH}$ and spinal motor neurodegeneration as seen in Werdnig-Hoffman disease (or spinal

\footnotetext{
* Correspondence: b.t.pollthe@amc.uva.nl

${ }^{3}$ Department of Pediatric Neurology, Academic Medical Center, Amsterdam,

The Netherlands

Full list of author information is available at the end of the article
}

muscular atrophy, SMA) was reported [5]. More reports of similar patients followed, indicating that the combined occurrence of $\mathrm{PCH}$ and bulbo-spinal motor neuron degeneration was not an incidental finding but a distinct syndrome [6-8]. In 1990, Barth et al. described 7 affected children from 5 families from a Dutch genetic isolate, with $\mathrm{PCH}$, microcephaly, severe extrapyramidal dyskinesia and absence of voluntary movement [9]. The extrapyramidal hyperkinesia in $\mathrm{PCH}$ was previously reported by Peiffer \& Pfeiffer (1977) [10]. In 1993, a first classification of $\mathrm{PCH}$ was proposed that included two subtypes, $\mathrm{PCH} 1$ and PCH2 [11]. PCH1 is characterized by anterior horn degeneration in the spinal cord with muscle weakness and hypotonia. $\mathrm{PCH} 2$ is distinguished by neonatal jitteriness, incoordination of sucking and swallowing, lack of voluntary motor development and grasping and - in most patients- almost complete absence of cognitive development [11].

Since the original description of $\mathrm{PCH}$, the phenotype has been significantly broadened. Nine different subtypes 
were added to the classification of $\mathrm{PCH}$, initially based upon distinct clinical, radiological or biochemical features (like optic atrophy, CSF lactate elevation), and later followed by the finding of associated gene defects (Table 1; Fig. 1). Inheritance of all PCH subtypes is autosomal recessive. Great clinical and neuroradiological variability exists within and between the different subtypes. Overall, $\mathrm{PCH}$ is a severe disorder with very limited or sometimes virtually absent developmental progress, and often early lethality. Most of the clinical neurological findings pertain to dysfunction of the cortex and basal ganglia, including severe intellectual disability, central motor impairments and epilepsy. Obvious cerebellar symptoms are very rarely reported in $\mathrm{PCH}$, despite the severe cerebellar involvement shown by neuroimaging. The clinical features and genetics of the different subtypes, as well as the differential diagnosis of $\mathrm{PCH}$ and possible disease mechanisms, will be discussed separately below.

\section{Main text}

PCH1

$\mathrm{PCH} 1$ is characterized by $\mathrm{PCH}$ with in addition bulbar and spinal motor neurodegeneration identical to spinal muscular atrophy (SMA) as seen in routinely stained spinal cord sections. Early reports describe PCH1 as a neonatally lethal disorder with polyhydramnios, congenital contractures, respiratory failure and severe muscle hypotonia [6,11]. Later studies describe sparing of the ventral pons and survival into puberty, thereby broadening the clinical and neuroradiological spectrum of PCH1 $[12,13]$. Currently, four genes are associated with $\mathrm{PCH} 1$ (PCH1A-D). Mutations in the vaccinia-related kinase 1 gene (VRK1, OMIM \# 607596)) are a very rare cause of PCH1; VRK1 mutations are described in one consanguineous PCH1 family of Ashkenazi Jewish origin [14]. The phenotype of these patients was atypical for $\mathrm{PCH}$ : patients had severe microcephaly from birth on while

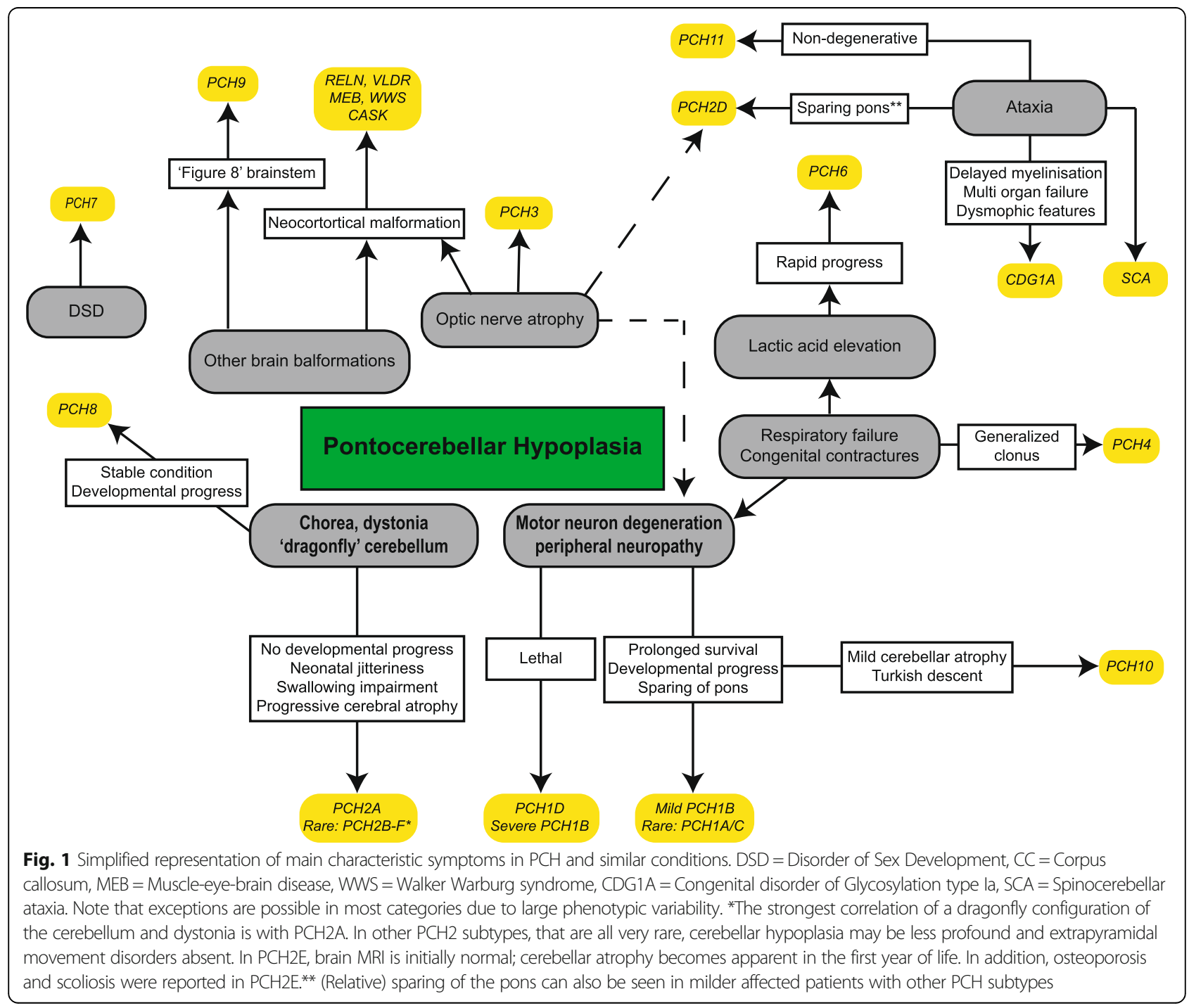


Table 1 Overview of PCH subtypes with associated gene defect. DSD = Disorders of Sex Development. * Imaging suggests postnatal onset of neurodegeneration in (a subset of) patients in this group

\begin{tabular}{|c|c|c|c|c|}
\hline Subtype & Symptoms/ distinctive features in addition to $\mathrm{PCH}$ & $\begin{array}{l}\text { Subcategory and } \\
\text { gene (\#OMIMnr) }\end{array}$ & Gene function & Key references \\
\hline \multirow[t]{4}{*}{$\mathrm{PCH} 1$} & \multirow{4}{*}{$\begin{array}{l}\text { Motor neuron degeneration, muscle weakness, } \\
\text { hypotonia, respiratory insufficiency, congenital } \\
\text { contractures }\end{array}$} & PCH1A: VRK1 (\#607596) & Neuronal migration & [14-16] \\
\hline & & PCH1B: EXOSC3 (\#614678) & mRNA degradation & {$[12,13,17]$} \\
\hline & & PCH1C: EXOSC8 (\#616081) & mRNA degradation & [18] \\
\hline & & PCH1D: SLC25A46 (*610826) & Mitochondrial fission and fusion & {$[19,20]$} \\
\hline \multirow[t]{6}{*}{$\mathrm{PCH} 2$} & \multirow{6}{*}{$\begin{array}{l}\text { Generalized clonus, impaired swallowing, } \\
\text { Dystonia, chorea, progressive microcephaly }\end{array}$} & PCH2A: TSEN54 (\#277470) & tRNA splicing & {$[21,22,24]$} \\
\hline & & PCH2B: TSEN2 (\#612389) & tRNA splicing & {$[21,25]$} \\
\hline & & PCH2C: TSEN34 (\#612390) & tRNA splicing & [21] \\
\hline & & PCH2D*: SEPSECS (\#613811) & Selenocysteine synthesis & [27-29] \\
\hline & & PCH2E: VPS53 (\#615851) & Unknown & [30] \\
\hline & & PCH2F: TSEN15 (\#617026) & tRNA splicing & [26] \\
\hline $\mathrm{PCH} 3$ & $\begin{array}{l}\text { Facial dysmorphism, optic atrophy, cerebellar } \\
\text { atrophy }\end{array}$ & PCLO $^{*}(\# 608027)$ & $\begin{array}{l}\text { Regulation synaptic protein } \\
\& \text { vesicle formation }\end{array}$ & [31-33] \\
\hline $\mathrm{PCH} 4$ & $\begin{array}{l}\text { Severe form of } \mathrm{PCH} 2 \text { with congenital contractures } \\
\text { and polyhydramnios }\end{array}$ & TSEN54 (\#225753) & tRNA splicing & {$[21,34]$} \\
\hline $\mathrm{PCH} 5$ & $\begin{array}{l}\text { Severe form of } \mathrm{PCH} 2 \text { with congenital contractures } \\
\text { and polyhydramnios (identical to } \mathrm{PCH} 4 \text { ) }\end{array}$ & TSEN54 (\#610204) & tRNA splicing & {$[37,38]$} \\
\hline $\mathrm{PCH} 6$ & $\begin{array}{l}\text { Hypotonia, seizures, elevated CSF lactate, } \\
\text { progressive supratentorial atrophy }\end{array}$ & RARS2* (\#611523) & Arginyl tRNA synthetase & {$[39,40]$} \\
\hline $\mathrm{PCH} 7$ & DSD, thin corpus callosum, enlarged ventricles & TOE1 (\#614969) & RNA processing & [52] \\
\hline $\mathrm{PCH} 8$ & $\begin{array}{l}\text { Abnormal muscle tone, dystonia, ataxia, no/little } \\
\text { disease progression. Non-degenerative. }\end{array}$ & CHMP1A (\#614961) & Regulation INK4A & [54] \\
\hline $\mathrm{PCH} 9$ & $\begin{array}{l}\text { Abnormal muscle tone, impaired swallowing, } \\
\text { corpus callosum agenesis and 'Fig. 8' configuration } \\
\text { of brainstem }\end{array}$ & AMPD2 (\#615809) & Regulation GTP synthesis & [55-58] \\
\hline $\mathrm{PCH} 10$ & $\begin{array}{l}\text { Abnormal muscle tone, seizures, motor neuron } \\
\text { degeneration, mild cerebellar hypoplasia/atrophy }\end{array}$ & CLP1 (\#615803) & tRNA splicing & [59-60] \\
\hline $\mathrm{PCH} 11$ & Non-progressive/ non-degenerative PCH. & TBC1D23 (\# 617695) & Intracellular vesicle transport & {$[61,62]$} \\
\hline
\end{tabular}

cognitive development seemed only mildly affected [14]. Later, VRK1 mutations turned out to be predominantly associated with motor neuron disease without $\mathrm{PCH}$ $[15,16]$. Subsequent studies found pathogenic mutations in EXOSC3 (OMIM \# 614678) in roughly half of the patients with PCH1 [12, 13, 17]. EXOSC3 encodes component 3 of the exosome complex, which is involved in mRNA degradation. Mutations in EXOSC3 were clinically associated with prolonged survival (mean age at death was nine months in patients with mutations versus three months in patients without EXOSC3 mutations) [13]. Respiratory failure, congenital contractures and polyhydramnios were rarely reported in the EXOSC3 mutation group [13]. Cerebellar hypoplasia was variably present and the pons was unaffected in a part of the patient group, depending on the genotype (Fig. 2a-d) $[12,13]$. Mutations in EXOSC8 (OMIM \# 61608), like EXOSC3 encoding a component of the exosome complex, were found to cause psychomotor retardation, severe muscle weakness, spasticity, hearing and vision impairment and motor neuron degeneration in 22 patients from three families. Neuroimaging showed hypoplasia of the cerebellum and corpus callosum, cortical atrophy and immature myelinisation [18]. Mutations in SLC25A46 (OMIM 610826) were shown to cause lethal pontocerebellar hypoplasia [19]. Mutations in this gene were also found to be the underlying genetic cause in the original Dutch $\mathrm{PCH} 1$ family, which was described by Barth to delineate the PCH1 phenotype as a distinct subtype of PCH [20]. With the identification of SLC25A46 mutations, for the first time a genetic basis for the most severe spectrum of the PCH1 phenotype was revealed.

\section{$\mathrm{PCH} 2$}

Probably $\mathrm{PCH} 2 \mathrm{~A}$ is the most prevalent and best characterized of all PCH subtypes. PCH2A is caused by homozygosity for a founder mutation (p.A307S) in the TSEN54 gene (OMIM \# 277470), which was identified by linkage analysis in 9 affected families from a Dutch genetic isolate [21]. Clinically, $\mathrm{PCH} 2 \mathrm{~A}$ is distinguished by generalized clonus and incoordination of sucking and swallowing in 


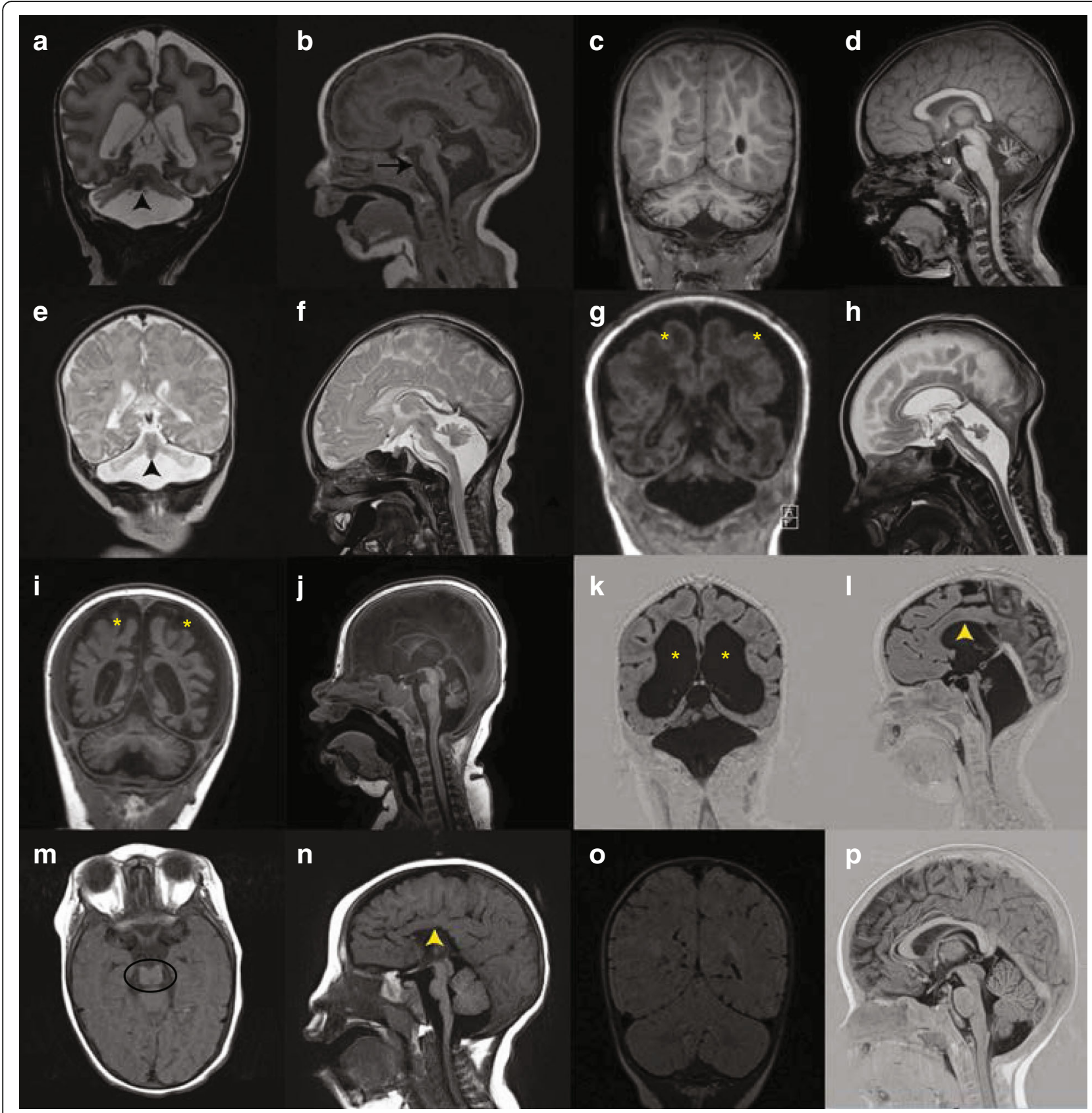

Fig. 2 (See legend on next page.) 


\begin{abstract}
(See figure on previous page.)
Fig. 2 MR images in different PCH subtypes. a-b. Coronal (a) and midsagittal (b) image of severely affected PCH1B patient (age 3 weeks, homozygous for the p. G31A mutation in EXOSC3), showing severe hypoplasia of cerebellar hemisphere with relative sparing of the vermis (indicated by arrowhead). The ventral pons is reduced in size but not completely flattened (indicated by arrow). c-d. Coronal (c) and midsagittal (d) image of PCH1B patient (age 2,5 months) with milder EXOSC3 mutations(the patient is homozygous for the p.D132A mutation). Cerebellar hypoplasia is very mild, with bilateral hyperintensities in the hili of the dentate nucleus. Size and shape of the ventral pons are normal. e-f. Coronal (e) and midsagittal (f) image of PCH2A patient (age 7 days, homozygous for the TSEN54, p.A307S mutation) with severe flattening of cerebellar hemispheres with relative sparing of the vermis (indicated by arrowhead) resulting in the 'dragonfly' configuration typical of PCH2A. This pattern is also seen in some PCH1 patients, as shown in 1A. The ventral pons is reduced in size but not completely flattened. $\mathbf{g - h}$. Coronal (g) and midsagittal (h) image of PCH4 patient (age 6 weeks, compound heterozygous for the p. A3075 mutation and a frameshift mutation in the TSEN54 gene). Note severe flattening of pons and severe hypoplasia of the cerebellum without sparing of the vermis and profound supratentorial atrophy (indicated by asterisks). i-j. Coronal (i) and midsagittal (j) image of a PCH6 patient (age 6 months, compound heterozygous for mutations in the RARS2 gene) with strikingly rapid progression of supratentorial atrophy (indicated by asterisks) and relatively slight atrophy of cerebellar hemispheres with normal pons and brainstem. $\mathbf{k}-\mathbf{I}$. Coronal $(\mathbf{k})$ and midsagittal (I) image of a PCH7 patient (age 8 months, with biallelic mutations in the TOE1 gene), showing severe pontocerebellar hypoplasia, equally affecting hemispheres and vermis. Note very thin corpus callosum and profound ventriculomegaly (indicated by asterisks and $\wedge$, respectively). $\mathbf{m}-\mathbf{n}$. Coronal and midsagittal image of a PCH9 patient (age 2 years, homozygous for a mutation in the AMPD2 gene), showing characteristic 'figure 8' shaped brainstem and corpus callosum agenesis (indicated by a circle and arrowhead, respectively).o-p. Coronal and midsagittal image of a control
\end{abstract}

the neonate. The toddler and young child suffer from spasticity, dystonia/chorea and epilepsy and show a lack of voluntary motor development and grasping and almost complete absence of cognitive development [21-23]. Patients often suffer from feeding problems requiring PEG feeding. In PCH2A sleeping disorders, recurrent infections, apneas and problems in temperature regulation are reported in the majority of patients. Microcephaly, usually absent in the neonatal period, is progressive, and caused by supratentorial atrophy. Mean OFD at the age of 5 years was -5.58 SD in a cohort of 33 patients studied by Sánchez and colleagues [24]. Life expectancy is reduced: more than $50 \%$ of patients die before puberty [24]. Homozygosity for the p.A307S mutation is strongly correlated with a 'dragonfly' configuration of the cerebellum on brain MRI, resulting from severely affected hemispheres ('the wings') and relative sparing of the vermis (' the body'; Fig. 2e-f) [22]. TSEN54 is part of the transfer-RNA (tRNA) splicing endonuclease complex: a complex involved in splicing of intron containing pre-tRNAs. The TSEN complex consists of four protein subunits: two catalytic (TSEN2 and TSEN34) and two structural (TSEN15 and TSEN54) ones. (Trotta 1997, Cell). Mutations in TSEN2, TSEN34 and TSEN15 rarely occur, resulting in a phenotype similar to $\mathrm{PCH} 2[22,25,26]$. These subtypes are classified as $\mathrm{PCH} 2 \mathrm{~B}, \mathrm{PCH} 2 \mathrm{C}$ and $\mathrm{PCH} 2 \mathrm{~F}$, respectively (respectively OMIM \# 612389, \# 612390 and \# 617026) [26]. Classification of the $\mathrm{PCH} 2$ subtypes was done chronologically, based on the order of the identification of respective disease genes. PCH2D is caused by mutations in the SEPSECS gene (OMIM \# 613811) and comprises a clinical spectrum with variable severity and some patients lack pontine hypoplasia [27-29]. In addition, patients with cognitive impairment and initial normal motor development with pediatric onset ataxia and motor decline have been described [29]. VPS53 mutations (OMIM \# 615851) were identified in four families of Jewish Moroccan ancestry and resulted in a $\mathrm{PCH}$-like phenotype (PCH2E) [30]. VPS53 is one of the four subunits composing the Golgi-associated retrograde protein complex, involved in transporting endosomes to the trans-Golgi network. In all ten patients, pregnancy was uncomplicated and head circumference was normal at birth. During the first months of life, a delay in motor and cognitive development became apparent. Progressive spasticity, spastic quadriplegia, multiple contractures, progressive microcephaly and seizures evolved during infancy. Osteoporosis and scoliosis were reported. Initial brain imaging was normal, but cerebellar atrophy was noted in the first year of life followed by cerebral atrophy. All patients had profound mental retardation [30].

\section{PCH3}

Pontocerebellar hypoplasia type 3 , in the literature also referred to as cerebellar atrophy and progressive microcephaly (CLAM), is characterized by pontocerebellar hypoplasia/atrophy, thin corpus callosum, progressive microcephaly, seizures, small stature, facial dysmorphism and in some patients optic nerve atrophy. The extrapyramidal movement disorders that are typically seen in PCH2 are absent [31-33]. In 2015, it was shown that mutations in the PCLO (\#608027) gene underlie PCH3 in a sibship form the Sultanate of Oman [31]. In 2009, a Turkish patient was described with a highly similar phenotype to the Omani patients [33]. The locus was mapped to the same region on chromosome $7 q$, in the region where the $P C L O$ gene is located, but it remains unknown whether aberrations in this gene underlie the phenotype in this patient as well.

\section{PCH4\&5}

Pontocerebellar hypoplasia type 4, previously reported in the literature as olivopontocerebellar hypoplasia due to involvement of the inferior olivary nuclei, is at the severe 
end of TSEN54-related $\mathrm{PCH}$ spectrum. Clinically, $\mathrm{PCH} 4$ presents as a severe form of $\mathrm{PCH} 2$, with prenatal onset of symptoms including polyhydramnios and congenital contractures, prolonged neonatal clonus, hypertonia and primary hypoventilation requiring prolonged mechanical ventilation. Survival beyond the neonatal period is rare [22]. Neuropathology in $\mathrm{PCH} 4$ shows delayed maturation and reduced growth of the cerebral cortex. Pericerebral fluid accumulation is regularly seen, and probably results from shrinkage of the brain due to severe atrophy [22]. Extensive gliosis and a decreased number of neurons in the thalamus and caudate nucleus have been reported [34]. The cerebellar hemispheres were severely hypoplastic and devoid of Purkinje cells, while at most only remnants of the dentate nucleus could be identified [35, 36]. Hypoplasia of the cerebellar vermis is variable; but overall the vermis is more severely affected than in PCH2 (Fig. 2g-h) [22]. An important neuropathological difference with $\mathrm{PCH} 2$ is the lack of folding of the inferior olivary nuclei, resulting in a horseshoe shape [35]. The more severe clinical course in $\mathrm{PCH} 4$ is reflected by the type of mutation in TSEN54. In PCH2A, patients are homozygous for the p.A307S missense mutation. In PCH4, patients are compound heterozygous with on one allele this hypomorphic missense mutation and a premature stop- or splice site (loss-of-function) mutation on the other allele. The latter combination of mutations is more detrimental for protein function and results in a more severe phenotype of $\mathrm{PCH} 4$ compared to $\mathrm{PCH} 2$. The distinction between $\mathrm{PCH} 4$ and PCH5 was initially based upon the presence of prenatal seizures and a more severely affected vermis compared to the hemispheres in a single PCH5 family [37]. However, Namavar et al. showed that, as in PCH4, compound heterozygous TSEN54 mutations, one being hypomorphic and the other being a loss-of-function mutation, underlie $\mathrm{PCH} 5$. The distinction of $\mathrm{PCH} 5$ as a separate subtype is therefore redundant [38].

\section{PCH6}

The canonical PCH6 phenotype consists of severe early onset epilepsy, progressive global atrophy including pons and cerebellum, lactic acidosis and/or mitochondrial respiratory chain defects [39]. PCH6 is caused by mutations in the nuclear encoded mitochondrial Arginine tRNA-synthetase (RARS2), which is responsible for catalyzing the specific attachment of Arginine to its cognate mitochondrial tRNA [40]. Currently, 31 patients with RARS2 mutations (OMIM \# 611523) have been reported [39-49]. None of them have biallelic null mutations, implicating that complete abolishment of mitochondrial tRNA-arg would be lethal. Splice site, nonsense or missense mutations are identified throughout the RARS2 gene, while no clear genotype-phenotype correlation could be established [49]. All patients surviving the neonatal period had severe developmental delay, and almost all suffered from refractory epilepsy. The majority of patients had elevated lactic acid in plasma or CSF. Respiratory chain deficiency in fibroblasts or muscle could not be confirmed in all these patients. Brain MRI showed cerebellar hypoplasia/atrophy of variable severity. Some early MRIs were normal or showed mild vermal hypoplasia, with often rapidly progressive atrophy of supra- and infratentorial structures (Fig. 2i-j) [49].

\section{$\mathrm{PCH7}$}

$\mathrm{PCH} 7$ is characterized by the rare combination of $\mathrm{PCH}$ with disorders of sex development (DSD). Patients show a severe developmental delay, profound truncal hypotonia with hypertonic limbs and brisk deep tendon reflexes, and seizures. Disorders of sex development were most apparent in 46, XY patients, who showed undervirilisation ranging from almost completely differentiated female external genitalia to micropenis with hypoplastic scrotum. In some XY patients, uterine or ovarian remnants could be found, while others had atrophic testes or no gonadal tissue at all [50-53]. Clinical information on XX patients was provided for three affected individuals. Two had normal external female genitals, and one patient had a prominent clitoris. In one patient the ovaries could not be detected by ultrasound, while the uterus was present [52]. Patients of both sexes manifest profound hypoplasia of pons and cerebellum, a thin corpus callosum and enlarged ventricles with irregular borders as a consequence of reduced cerebral white matter (Fig. 2k-1) [51, 52]. Only one neuropathological report is available, provided by Anderson in 2011, which showed cerebral atrophy with a profound reduction in white matter. The cerebellar hemispheres were almost absent; only rudimentary folia devoid of neurons could be identified. The vermis was relatively spared. The ventral pons lacked pontine nuclei, while the pontine tegmentum was relatively normal. The inferior olivary nuclei could not be identified [51]. In 2017, biallelic mutations in TOE1 (OMIM \# 614969) were reported in 12 families with $\mathrm{PCH} 7$ [52].

\section{PCH8}

Only three families with $\mathrm{PCH} 8$ have been reported. Patients have microcephaly, a severe developmental delay (although some patients were able to walk independently), dystonic posturing and/or choreiform movements. Some patients had (congenital) contractures and seizures. In contrast with the other $\mathrm{PCH}$ subtypes, $\mathrm{PCH} 8$ seems to be a stable neurologic condition without clear evidence of disease progression. Brain imaging showed profound pontocerebellar hypoplasia, a thin but fully formed corpus callosum and a decrease in cerebral white matter in all patients. In patients who had multiple brain MRIs, no clear signs of ongoing neurodegeneration were noted [54]. 
PCH8 might be considered as a 'non-degenerative' form of $\mathrm{PCH}$ and is caused by mutations in the CHMP1A gene (OMIM \# 614961). CHMP1A is involved in chromatin modelling and cell proliferation [54].

\section{PCH9}

PCH9 is characterized by progressive microcephaly, profound neurodevelopmental delay, cortical visual impairment, impaired swallowing, spasticity with neonatal clonus, brisk deep tendon reflexes and truncal hypotonia. Facial dysmorphisms are reported with dental abnormalities in a minority of patients. The presence of axonal neuropathy is reported in older patients and is probably age-dependent [55-57]. Brain MRI showed pontocerebellar hypoplasia, severe hypoplasia of the corpus callosum with, on axial images, a characteristic 'figure 8 ' shape of the mesencephalon, with hypoplastic cerebral peduncles (Fig. 2m-n) [55-58]. PCH9 is caused by mutations in the AMPD2 gene (OMIM \# 615809), which encodes one of the three adenosine monophosphate deaminases. Interestingly, mutations in the same gene have also been associated with spastic paraplegia 63 (SPG63; OMIM \#615686).

\section{PCH10}

Nine families of Turkish origin have been reported with PCH10 [59, 60].Mutations in CLP1 has been identified as the causal gene defect (OMIM \# 615803). CLP1 interacts with the TSEN complex and is also involved in tRNA splicing (see below). Clinical characteristics are a severe developmental delay, seizures, progressive spasticity, facial dysmorphism, microcephaly and signs of axonal neuropathy of both motor and sensory neurons. Brain MRI showed a thin corpus callosum, delay in myelinisation and hypoplasia of the ventral pons/thinning of the brainstem. Atrophy of the cerebellum is, if present at all, very mild compared to the other subtypes of $\mathrm{PCH}$.

\section{PCH11}

Seven families with PCH11 have been reported. Patients were homozygous for truncating or splice site mutations in the TBC1D23 gene (OMIM \# 617695) [61, 62]. $\mathrm{PCH} 11$ is characterized as another non-degenerative form of $\mathrm{PCH}$ and is characterized by a severe neurodevelopmental delay, microcephaly and hypotonia. Seizures were reported in $2 / 13$ patients. Some patients were able to walk alone. Specific cerebellar symptoms like ataxia were reported in roughly half of the patients; this implies that some degree of voluntary movement was present in those patients. Brain MRI showed non-progressive hypoplasia of pons and cerebellum with hypoplasia of the corpus collosum [61, 62].

\section{Management and treatment}

No curative treatment is available for any type of $\mathrm{PCH}$. Treatment is symptomatic in all subtypes. $\mathrm{PCH} 2 \mathrm{~A}$ is the most prevalent subtype of $\mathrm{PCH}$, and the only type in which adequate patient numbers allowed a systematic study of its clinical course. PCH2A patients often suffer from feeding problems starting immediately after birth requiring gavage or PEG feeding. Sleep apnoea, which is a frequently reported and life-threatening complication in $\mathrm{PCH}$, and which may lead to sudden infant death, can be detected by sleep monitoring [24]. Seizures in $\mathrm{PCH} 2 \mathrm{~A}$ are difficult to treat, but a relatively good effect on phenobarbital and topiramate is reported (resulting in a reduction in seizure frequency in 11 out of 15 and 6 out of 7 patients, respectively) [24]. Choreathetoid movements are present in about $90 \%$ of patients. [22, 24] Opisthotonic posturing can be prevented by flexure of the large joints. An ergonomically shaped wheelchair and physiotherapy can be beneficial in achieving this. In one $\mathrm{PCH} 2$ patient, an improvement of dystonic crises and choreoathetosis upon treatment with Levodopa was reported [63]. Rhabdomyolysis and strongly elevated serum creatine kinase have been repeatedly reported and should be carefully monitored, especially during episodes of infection [23, 64-66]. Muscle biopsies and serum CK measurements of some $\mathrm{PCH} 2$ patients without any muscular symptoms showed evidence for a subclinical myopathy in a part of the $\mathrm{PCH} 2$ population [65].

$\mathrm{PCH} 9$ has been considered to be a potentially treatable disorder, because administration of a purine nucleotide precursor (AICAr) could rescue the phenotype at a cellular level. Follow-up experiments are needed, because it was shown that administering of AICAr tends to inhibit axonal growth in mouse cultures neurons [55].

\section{Differential diagnosis of pontocerebellar hypoplasia/atrophy}

Cerebellar hypoplasia and cerebellar atrophy are both relatively common and nonspecific findings occurring in a very heterogeneous group of disorders [67]. Hypoplasia refers to a static condition in which the cerebellum has a normal shape but is too small, while atrophy refers to progressive loss of cerebellar tissue, resulting in progressive widening of interfolial spaces. The distinction between hypoplasia and atrophy may be easy to make on theoretical grounds; in practice however this can be challenging or even impracticable when based on a single brain imaging study.

Neuropathology reports in PCH2A mention both hypoplastic features with shortening of cerebellar folia with reduced branching ('stunted folial growth') and degenerative changes like thinning of the cerebellar cortex [35]. A mechanism of prenatal onset neurodegeneration is assumed, which is reflected by the ongoing postnatal neurodegeneration of the cerebral cortex, resulting in progressive 
microcephaly and widening of the lateral ventricles. The use of the term 'hypoplasia' in PCH is explained by historic reasons: at the time of the first descriptions of $\mathrm{PCH}$, the concept of prenatal onset neurodegenerative disorders was yet unknown. Therefore, it was common to describe this congenital defect as 'hypoplasia'.

Many metabolic disorders and genetic syndromes display cerebellar hypoplasia/atrophy. Careful assessment of the neuroimaging pattern is essential to evaluation. In $\mathrm{PCH}$ vermal growth is relatively spared compared to the cerebellar hemispheres, while in disorders like Joubert syndrome and Dandy-Walker malformation the vermis is mainly affected. The molar tooth sign, caused by elongation and a more horizontal course of the superior cerebellar peduncle, is characteristic of Joubert syndrome. While cerebellar hypoplasia has a broad differential diagnosis, the presence of pontine hypoplasia significantly narrows down the diagnostic options. Pontine hypoplasia affects the basis of the pons, and is mainly due to loss of ventral pontine neurons and transverse pontine fibers. However, the combination of pontine and cerebellar hypoplasia, does not automatically result in a diagnosis of $\mathrm{PCH}$ as discussed here. The use of the term ' $\mathrm{PCH}$ ' is not uniform which may give rise to confusion. Some of the disorders that share pontine and cerebellar hypoplasia as a feature on MRI are discussed below (and Table 2).

\section{Congenital disorder of glycosylation type 1A (CDG1A)}

Congenital disorders of Glycosylation type 1a (CDG1a; OMIM \#212065) present with global (ponto)cerebellar hypoplasia with superimposed atrophy on brain MRI $[68,67]$. In addition to $\mathrm{PCH}$, supratentorial atrophy with enlarged ventricles and delayed myelinisation can be present. [67, 68] Clinical presentation of CDG1a is highly variable: ranging from severe neonatal onset multi-organ failure to a stable neurological condition with moderate mental retardation and ataxia. Typical dysmorphic features are inverted nipples and abnormal fat distribution [69-71]. CDG1a is caused by autosomal recessive mutations in the $P M M 2$ gene and can be excluded by isoelectric focusing of transferrines. Cerebellar involvement is also reported in several other (rare) forms of CDG [72].

\section{Pontocerebellar hypoplasia with neocortical malformations}

CASK - related disorders Loss of function mutations and (partial) deletions of the CASK gene, which is located on the $\mathrm{X}$ chromosome, are associated with microcephaly with pontine and cerebellar hypoplasia (MICPCH, OMIM \# 300749) [73]. Pons and cerebellum can be severely hypoplastic, resembling $\mathrm{PCH}$. Neocortical dysgenesis and malformations can be present in addition (e.g. reduction of number and complexity of frontal gyri and blurring of neocortical grey-white matter border) [73, 74]. Loss-of-function mutations and deletion often occur de novo. CASK- related $\mathrm{PCH}$ is clinically highly variable but is distinguished form $\mathrm{PCH} 1$ and $\mathrm{PCH} 2$ by the absence of motor neuron degeneration and chorea, respectively. $C A S K$ Patients show additional features like minor facial dysmorphisms (e.g. a round face with small chin, large nasal bridge), sensorineural hearing loss and ophthalmologic abnormalities [75]. The degree of cerebellar hypoplasia is variable, while the cerebellar hemispheres and vermis are equally involved without sparing of the vermis as seen in $\mathrm{PCH} 1$ and $\mathrm{PCH} 2$. The cerebellar hemispheres show asymmetry in some patients. Although developmental delay is severe, some patients achieve milestones like independent sitting or walking and speaking few single words [75].

Genes involved in the organization of microtubuli Microtubuli play a key role in development of the brain by providing mechanical forces needed for cell division, axon guidance and neuronal migration [76, 77]. Mutations in several genes involved in tubulin formation are associated with a range of cortical malformations including lissencephaly and polymicrogyria, often combined with variable degrees of cerebellar hypoplasia and brain stem malformations [77]. TUBA1A mutations (OMIM \# 611603 ) account for about $30 \%$ of patients with lissencephaly and cerebellar hypoplasia [78]. Other genes in the tubulin pathway that are associated with similar neuroradiological features are: TUBB2B, TUBB3, TUBB5 and TUBA8 [77].

RELN and VLDLR mutations Autosomal recessive mutations in RELN (OMIM* 600514) result in lissencephaly with severe pontocerebellar hypoplasia and abnormal hippocampus [77, 79]. In contrast to $\mathrm{PCH} 2$, the cerebellar vermis is also very hypoplastic and often completely lacks foliation [78]. The Reelin signaling pathway is important for neuronal migration during development $[77,79]$. The very low density lipid receptor (encoded by the VLDLR gene, OMIM\# 224050) is an important player in this pathway and aberrations of VLDLR result in a similar, although generally milder, neurodevelopmental phenotype. Cortical malformations are milder, cerebellar ataxia is non-progressive and some patients have been described with a characteristic quadrupedal gait $[80,81]$.

$\alpha$ - dystroglycan related dystrophies Defects in O-mannosyl-linked-glycosylation of $\alpha$ - dystroglycan underlie this group of heterogeneous congenital muscular dystrophies. The associated phenotypes form a wide clinical spectrum and are roughly divided in three main groups, depending 
Table 2 Differential diagnosis of Pontocerebellar Hypoplasia (PCH)

\begin{tabular}{|c|c|c|c|}
\hline Disease & Distinctive features & Gene(s) involved & references \\
\hline $\begin{array}{l}\text { Congenital disorder of } \\
\text { Glycosylation la (CDGla) }\end{array}$ & $\begin{array}{l}\text { Clinical: neonatal onset multi organ failure, } \\
\text { dysmorphic features, ataxia. Microcephaly. } \\
\text { MRI: global PCH with superimposed atrophy, } \\
\text { supratentorial atrophy, ventriculomegaly, } \\
\text { delayed myelinisation. }\end{array}$ & PMM2 & {$[68,69,72]$} \\
\hline CASK- related disorders & $\begin{array}{l}\text { Clinical: facial dysmorphism, sensorineural } \\
\text { hearing loss, ophthalmologic abnormalities. } \\
\text { Developmental progress in a subgroup of } \\
\text { patients. No MND or chorea. Progressive } \\
\text { microcephaly. } \\
\text { MRl: variable degree of PCH, equally affecting } \\
\text { hemispheres and vermis. Cortical malformations } \\
\text { can be present. }\end{array}$ & CASK & {$[73-76]$} \\
\hline Tubulin defects & $\begin{array}{l}\text { Clinical: DD, seizures. Progressive microcephaly. } \\
\text { Optic atrophy in some cases. } \\
\text { MRI: cortical malformations (eg lissencephaly, } \\
\text { polymicrogyria) with cerebellar hypoplasia and } \\
\text { brainstem malformations. }\end{array}$ & TUBA1A, TUBB2B, TUBB3, TUBB5, TUBA8 & {$[77-79]$} \\
\hline RELN \& VLDLR mutations & $\begin{array}{l}\text { Clinical: Severe DD, hypotonia, epilepsy, } \\
\text { nystagmus. In VLDLR: non-progressive ataxia, } \\
\text { quadrupedal gait. } \\
\text { MRI: lissencephaly, severe PCH and abnormal } \\
\text { hippocampus, milder in VLDLR. }\end{array}$ & $R E L N, V L D L R$ & [80-82] \\
\hline $\begin{array}{l}\text { a- dystroglycan related dystrophies } \\
\text { (WWS, MEB, Fukuyama congenital } \\
\text { muscular dystrophy) }\end{array}$ & $\begin{array}{l}\text { Clinical: severe DD, muscle weakness with } \\
\text { increased CK, ophthalmologic abnormalities. } \\
\text { WWS at the severest end of the spectrum. } \\
\text { MRI: wide spectrum of brain malformations } \\
\text { including cobblestone lissencephaly, PCH, } \\
\text { congenital hydrocephalus. }\end{array}$ & $\begin{array}{l}\text { POMT1, POMT2, POMGnT1, LARGE, FKTN, } \\
\text { FKRP, ISPD, FKR, FKRP }\end{array}$ & {$[83,84,85]$} \\
\hline $\begin{array}{l}\text { X-linked Hoyeraal-Hreidarsson } \\
\text { syndrome }\end{array}$ & $\begin{array}{l}\text { Clinical: IUGR, microcephaly, failure to thrive, } \\
\text { progressive bone marrow failure, aplastic } \\
\text { anemia, combined immunodeficiency, some } \\
\text { symptoms of DC. } \\
\text { MRI: PCH, delayed myelinisation, focal high } \\
\text { intensities in brainstem and thalamus, } \\
\text { subcortical calcifications. }\end{array}$ & DKC1 & {$[86-87]$} \\
\hline $\begin{array}{l}\text { Pediatric onset Spinocerebellar } \\
\text { Ataxia }\end{array}$ & $\begin{array}{l}\text { Clinical: Ataxia, developmental progress, some } \\
\text { cases with retinitis pigmentosa or cone-rod } \\
\text { dystrophy. } \\
\text { MRI: (ponto) cerebellar hypoplasia/atrophy, } \\
\text { no supratentorial atrophy. }\end{array}$ & ITPR1, ATXN7, ATXN2 & [88-92] \\
\hline Extreme prematurity (<32 weeks) & $\begin{array}{l}\text { Clinical: motor and cognitive impairment } \\
\text { of variable degree, autism spectrum disorders } \\
\text { MRI: PCH, signs of cerebellar or cerebral injury, } \\
\text { eg hemorrhage. Non progressive. }\end{array}$ & $\mathrm{n} / \mathrm{a}$ & [95-97] \\
\hline
\end{tabular}

MND motor neuron degeneration, DD developmental delay, CK creatine kinase, WWS Walker-Warburg syndrome, MEB Musce Eye Brain disease, IUGR Intrauterine Growth Retardation, $D C$ dyskeratosis congenita

on clinical severity: Fukuyama congenital muscular dystrophy, muscle-eye-brain disease and Walker-Warburg syndrome (WWS). Main characteristics are muscle weakness with increased serum CK, delayed motor development and severe cognitive impairment and opthalmological abnormalities (e.g. optic nerve atrophy, congenital glaucoma). Brain malformations include dysplastic supratentorial malformations (e.g. cobblestone lissencephaly or polymicrogyria) and cerebellar and pontine hypoplasia [82]. Also patients with a normal appearing brain MRI are reported [83]. Isolated cerebellar involvement occurs rarely [84].

\section{X-linked Hoyeraal-Hreidarsson syndrome}

$\mathrm{X}$-linked Hoyeraal-Hreidarsson syndrome (XL-HHS) is characterized by intrauterine growth retardation, microcephaly, failure to thrive, developmental delay combined with progressive bone marrow failure, aplastic anemia and combined immunodeficiency $[85,86]$. Neuroradiologic features are (ponto)cerebellar hypoplasia, hypoplastic corpus callosum, delayed myelination, focal high intensities in the brainstem and thalamus, and subcortical calcifications [87]. XL-HHS is caused by mutations in the $D K C 1$ gene (OMIM \# 305000). DKC1 is also involved in dyskeratosis congenital (DC), a syndrome characterized 
by bone marrow failure and a characteristic triad of abnormal skin pigmentation, oral leucoplakia and nail dystrophy $[85,86]$. In XL-HHS, these characteristic mucocutaneous features of DC can be present $[85,87]$.

\section{Spinocerebellar ataxias}

Hypoplasia and/or atrophy of the cerebellum at early age can manifest in pediatric onset types of spinocerebellar ataxia (SCA). The SCA's refer to a heterogeneous group of autosomal dominant inherited ataxia's of varying severity and age of onset [88]. Brainstem involvement is not a regular finding in SCA, but has been reported in later disease stages of very severe infantile onset SCA2 and SCA7 [89-91]. Usually other findings like retinitis pigmentosa or cone-rod dystrophy are present in SCA2 and SCA7, that distinguish these conditions from $\mathrm{PCH}$. More recently, it has been shown that mutations in ITPR1, can result in severe pontocerebellar hypoplasia, mimicking PCH [93]. Supratentorial atrophy was absent in this patient, while she clearly showed developmental progress.

\section{ATADA3 deletions/mutations}

Biallelic deletions of the ATAD $3 A$ gene are associated with a lethal prenatal onset disorder characterized by polyhydramnios, contractures, severe pontocerebellar hypoplasia, microcephaly, abnormal basal ganglia and abnormalities of cortical gyration [94]. The ATAD3 gene cluster comprises three genes that are arranged in tandem: ATAD3C, ATAD3B and ATAD3A [94]. Both homozygous deletions affecting the $A T A D 3 A / A T A D 3 B$ genes as well as some combinations of a null allele with missense mutations in $A T A D 3 A$ are associated with this lethal phenotype. Milder mutations in $A T A D 3 A$ and deletions involving $A T A D 3 B / A T A D 3 C$ genes appear to be associated with a milder clinical course [94, 95]. The ATAD3 gene cluster is involved in mtDNA organization and cholesterol metabolism [95].

\section{Extreme prematurity}

Extreme prematurity (gestational age $<32$ weeks) is associated with an increased risk of cerebellar hypoplasia of various degrees. In severely affected patients, neuroradiologic imaging can mimic $\mathrm{PCH}$ [96]. The extremely rapid growth of the cerebellum in the third trimester results in an increased vulnerability of the premature cerebellum. Several (combined) mechanisms of preterm cerebellar injury are suggested, roughly consisting of ischemic of hemorrhagic destructive cerebellar lesions and cerebellar underdevelopment. In addition, effects of supratentorial injury on the development of cerebellum and brainstem trough involvement of cortico-cerebellar connections have been suggested [97, 98].
Brossard-Racine et al. reviewed the clinical outcome in preterm infants. Both motor and cognitive impairment are significantly associated with direct cerebellar injury. Also autistic features are often reported, especially when the cerebellar vermis is involved. The effects of indirect cerebellar injury (e.g. cerebellar underdevelopment associated with cerebral injury) on long-term development are less well studied and studies often show conflicting results [98].

\section{Pathomechanisms of $\mathrm{PCH}$ \\ $P C H$ related to defects in $t R N A$ splicing}

Homozygosity for the p.A307S mutation in TSEN54 is the most prevalent cause of $\mathrm{PCH}$. As discussed above, TSEN54 is one of the four subunits of the transfer-RNA splicing endonuclease complex (TSEN-complex). Mutations in TSEN2, TSEN34 and TSEN15 occur very rarely. The TSEN complex is involved in the cleavage of intron containing tRNAs (Fig. 3a). tRNAs contain an anticodon sequence by which they recognize the codon of the mRNA template that is being translated. By transferring the required amino acid to the ribosomal complex for incorporation in the peptide chain, tRNAs are essential for protein translation. The human genome contains 506 genes that encode tRNAs; providing templates for multiple tRNAs for each codon. Only a minority of these tRNA genes (6\%) contains an intron. For some amino acids however, the vast majority of tRNAs is intron containing (e.g. tRNA-Tyr (GTA) and tRNA-Ile (TAT)) (http://gtrnadb.ucsc.edu/). It is hypothesized that TSEN-complex defects result in impaired tRNA splicing and subsequently a decrease in protein translation. However, results of in vitro experiments studying the effect of the A307S mutation on tRNA splicing are ambiguous. Budde et al. reported no unspliced tRNA-Tyr products in patient fibroblasts, measured by RNA blot analysis [21].

CLP1, involved in PCH10, phosphorylates the $5^{\prime}$ ends of 3' tRNA halves after splicing by the TSEN complex, thereby preparing re-ligation of the spliced tRNA halves by an unknown ligase. CLP1 is also known to interact with the TSEN complex; an interaction required for efficient tRNA splicing. It was shown that the R140H mutation in CLP1 hampers interaction with the TSEN complex, and thereby impairs tRNA splicing in vitro. In patient derived iNeurons, an accumulation of some pre-tRNAs with a corresponding reduction in mature tRNAs was found $[59,60]$.

\section{$P C H$ related to other defects in RNA processing and protein translation}

Two subunits of the RNA exosome complex are involved in PCH. EXOSC3 functions as a RNA binding unit and is located in the cap of the complex, while EXOSC8 is one of the six subunits that composes the core ring. The exosome complex is important for 


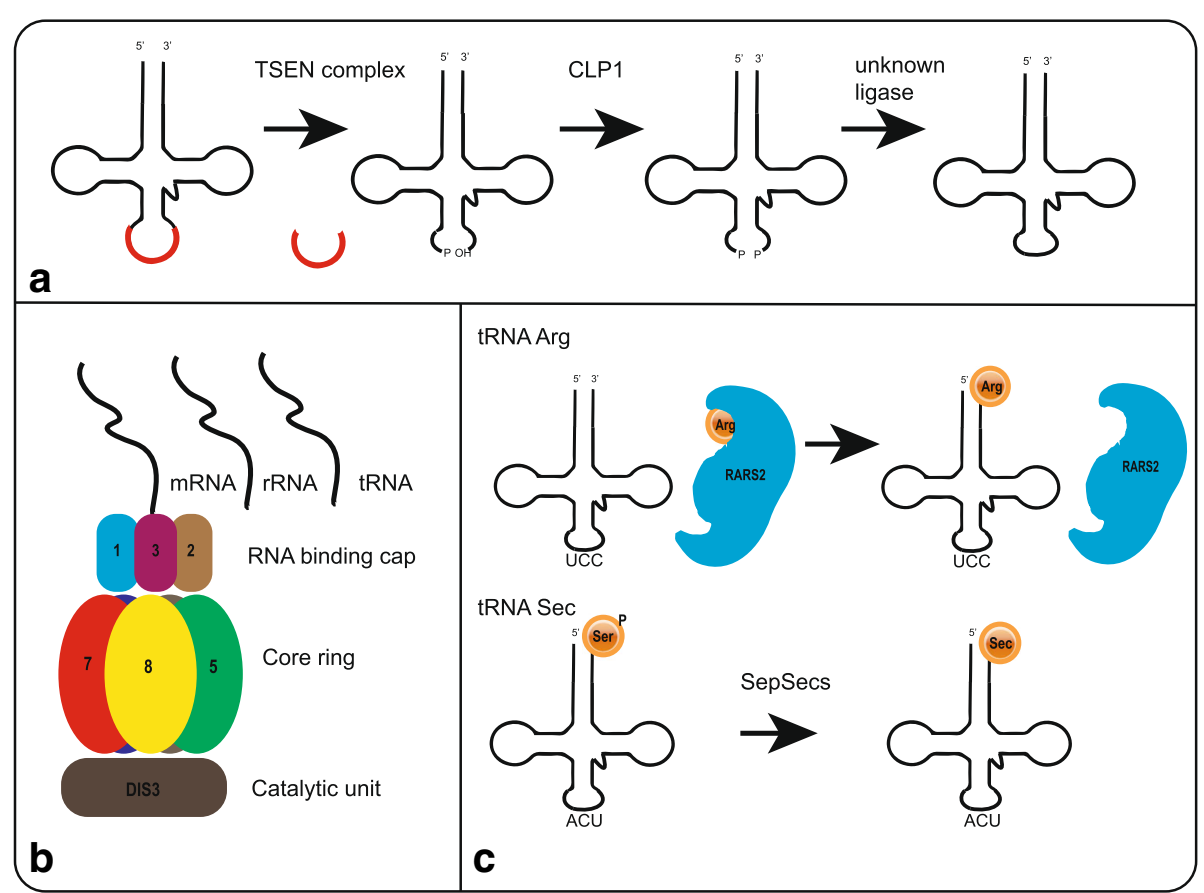

Fig. 3 Schematic representation of main pathways involved in PCH. A. Schematic and simplified representation of tRNA splicing by the TSEN complex and CLP1. B. Schematic figure of the exosome complex including EXOSC3, located in the RNA binding cap, and EXOSC8, located in the core ring. The exosome complex processes mRNA, rRNA and presumably tRNA. C. Upper: charging of tRNA-Arg by RARS2. Lower: conversion of Sec-tRNA-Ser to Sec-tRNA-Sec by SEPSECS

degradation of mRNA and ribosomal RNA (rRNA) fragments and for maturation of certain rRNAs (Fig. 3b and see Fasken et al. for comprehensive summary) [99]. A role in tRNA degradation in human has been implied based on roles of the exosome complex in tRNA metabolism in yeast [100, 101]. Modeling of human EXOSC3 mutations in S. cerevisiae affected pre-rRNA processing [102]. Why defects in rRNA processing specifically affects neurons remains unknown.

SEPSECS, mutated in PCH2D, encodes the O-phosphoseryl-tRNA(Sec) selenium transferase enzyme, which is needed for the final step in the synthesis of selenocystein. Selenocystein is essential for the synthesis of selenoproteins, but lacks its own tRNA-synthetase [27-29]. Therefore, to synthesize selenocystein, a Serine is transferred to a tRNA sec and is then via several steps converted to a Sec-tRNA-Sec complex (Fig. 3c) [103]. PCH6 is caused by mutations in the nuclear encoded mitochondrial Arginine tRNA-synthetase (RARS2), which is responsible for catalyzing the specific attachment of Arginine to its cognate mitochondrial tRNA (Fig. 3c) [40]. In patient fibroblast, a reduction in the amount of mitochondrial tRNA-arg was found, but almost all molecules were charged. Authors suggest instability of the uncharged product to explain for this [40].

TOE1, mutated in $\mathrm{PCH} 7$, localizes to and is important for Cajal body maintenance, and a role of TOE1 in splicing of pre-mRNA was suggested [104]. Recent studies provide evidence for a role of TOE1 in the maturation of small nuclear RNAs and show accumulation of incompletely processed snRNAs in patient fibroblasts [52]. However, it remains unknown why defects in TOE1 specifically affect brain and gonadal development.

\section{Other mechanisms in $\mathrm{PCH}$}

In some of the other $\mathrm{PCH}$ subtypes however, the link with RNA metabolism or protein translation is less clear. For example, SLC25A46 (PCH1D) has a role in balancing mitochondrial fission and fusion and maintenance of mitochondrial cristae. Phenotypes associated with SLC25A46- mutations range from optic nerve atrophy and cerebellar atrophy to lethal $\mathrm{PCH}$ at the most severe end of the spectrum. Vaccinia related kinase1, encoded by VRK1 and mutated in PCH1A, is implied in several fundamental cellular processes as coordination of cell division and regulation of Cajal body assembly $[105,106]$. Knockdown of VRK1 in a mouse model resulted in impaired neuronal migration in the cortex and influenced the neuronal progenitor cell cycle [107]. VPS53, involved in PCH2E, is one of the four subunits composing the Golgi-associated retrograde protein (GARP) complex. This complex is involved in retrograde transport to the trans-Golgi network [30]. $P C L O$, involved in $\mathrm{PCH} 3$, encodes piccolo, a presynaptic vesicle protein with a role in synaptic vesicle organization. 
In addition, a role in regulating presynaptic ubiquitination and proteostasis has been reported [108]. Piccolo was shown to be essential for the maintenance of synaptic integrity and loss of piccolo leads to degradation of multiple synaptic proteins and eventually to the disassembling of the synapse [109]. It was therefore suggested that the degeneration of synapses due to absence of piccolo might trigger an apoptotic signal in neurons in $\mathrm{PCH} 3$ patients [31]. CHMP1A (PCH8) has a function in chromatin modelling and cell proliferation. It is assumed that CHMP1A, via interaction with BMI1, has a role in inhibition of INK4, which is a negative regulator of stem cell proliferation [54]. PCH9 is caused by mutations in the AMPD2 gene, which encodes one of the three adenosine monophosphate deaminases. AMPD2 converts AMP to IMP, which is then further processed to form guanine nucleotides. It was shown that defects in AMPD2 result in a depletion of guanine nucleotides and an accumulation of specific adenosine nucleotides [55]. This accumulation inhibited de novo purine synthesis by a negative feedback mechanism. Of the three AMPD paralogs, AMPD2 is predominantly expressed in the cerebellum, which possibly explains why cerebellar structures are most severely affected in PCH9 [55]. PCH11 is caused by truncating and splice site mutations in TBC1D23 gene. TBC1D23 is involved in regulation of trans-Golgi membrane trafficking [61]. Intracellular vesicle transport was shown to be affected in patients fibroblasts and down regulation of $T B C 1 D 23$ in mice resulted in abnormal neural positioning in the cortex [62].

Alteration of RNA metabolism/ protein translation is a common mechanism behind at least some of the $\mathrm{PCH}$ subtypes. However, it remains unknown why the cerebellum is specifically affected by these defects in processes that seem vital to other organs as well. The third trimester is a period of tremendous growth for the developing cerebellum. It is hypothesized that the cerebellum is extremely vulnerable to alterations in RNA and/or protein metabolism in this specific time-window $[23,110]$. This might partly explain for the cerebellum-specific involvement.

\section{Incidence of $\mathrm{PCH}$}

$\mathrm{PCH}$ is a very rare disorder. The exact incidence of $\mathrm{PCH}$ is unknown. PCH2A caused by homozygosity for the p.A307S mutation in TSEN54 is the most frequent type of $\mathrm{PCH}$ (Fig. 4). The estimated incidence of $\mathrm{PCH} 2 \mathrm{~A}$ is <1:200.000 [24]. We identified mutations in $\mathrm{PCH}$ related genes in 42 patients in routine diagnostic care between 2012 and 2017. Twenty out of those 42 patients were homozygous for the p.A307S mutation, 13 patients had mutations in EXOSC3, four patients harboured mutations in $R A R S 2$, one patient had SEPSECS mutations and one had mutations in AMPD2. We also identified hetero- or hemizygous CASK

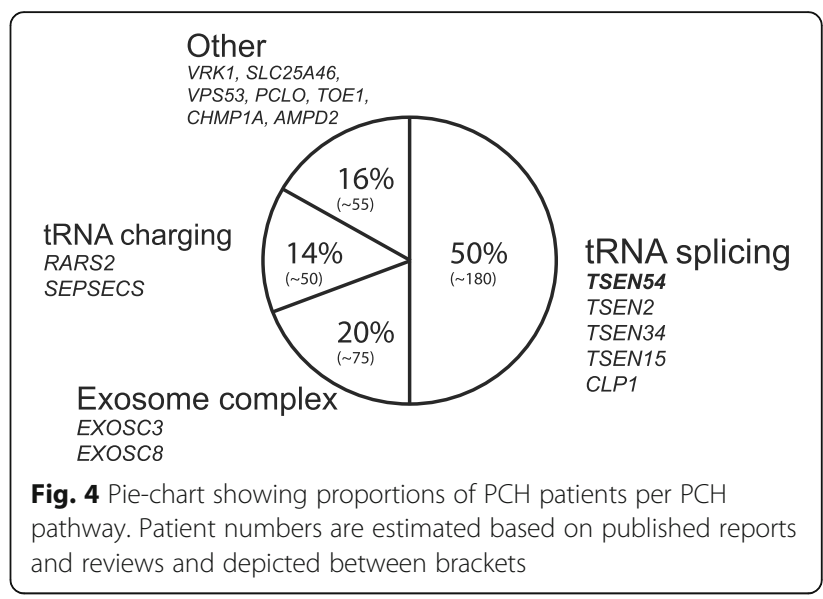

mutations in nine patients, indicating that this is a frequent cause of a condition similar to $\mathrm{PCH}$.

\section{Genetic counselling and prenatal testing}

Counselling regarding recurrence risk should be provided and reproductive options discussed. Preconception carrier screening is offered for $\mathrm{PCH} 2 \mathrm{~A}$ in a closed community in the Netherlands [111]. Since 2010, seven carrier couples were identified in this community. In families were the causal genetic defect is identified, preimplantation genetic diagnosis (PGD) or invasive prenatal testing should be offered for family planning. Prenatal detection of $\mathrm{PCH}$ by ultrasound is unreliable, since it often fails to detect cerebellar abnormalities at time of the routine 20 weeks screening for structural abnormalities [111-113].

\section{Discussion \& Conclusion}

Due to development and appliance of next generation sequencing techniques, many new $\mathrm{PCH}$ related genes and phenotypes have been described. However, there are still many patients with a clinical diagnosis of $\mathrm{PCH}$, in whom no mutations in any of the known $\mathrm{PCH}$ related genes is identified.The current classification of $\mathrm{PCH}$ comprises a heterogeneous group of disorders, ranging from lethal conditions with prenatal onset as PCH1D and $\mathrm{PCH} 4$ to milder forms where disease progression is less devastating allowing survival into adolescence as (some subtypes of) PCH1B and PCH2D. Unfortunately, by including such a broad range of phenotypes, the current classification undermines two important aspects of the original description of $\mathrm{PCH}$. Both nondegenerative conditions (e.g. $\mathrm{PCH} 8$ and $\mathrm{PCH} 11$ ) and disorders with a postnatal onset (e.g. $\mathrm{PCH} 2 \mathrm{D}, \mathrm{PCH} 2 \mathrm{E}$ and $\mathrm{PCH} 10$ ) are included in the $\mathrm{PCH}$ classification, essentially ignoring the fact that $\mathrm{PCH}$ was originally defined as a disorder of prenatal onset neurodegeneration. $\mathrm{PCH} 2 \mathrm{D}$ and $\mathrm{PCH} 2 \mathrm{E}$ were initially described by the authors as progressive cerebellocerebral atrophy (PCCA and PCCA2, 
respectively), but eventually ended up as subtypes of $\mathrm{PCH}$. $\mathrm{PCH} 3$ was originally referred to as cerebellar atrophy and progressive microcephaly (CLAM), because neuroimaging resembled cerebellar atrophy rather than hypoplasia. The patient numbers reported in $\mathrm{PCH} 3-11$ are small (with only $\mathrm{PCH} 6$ due to RARS2 mutations occurring relatively common), therefore the full clinical and radiological spectrum of these disorders is not completely revealed yet. The current classification of $\mathrm{PCH}$ is prone to lead to confusion, because at this point it is unclear which disorders should be classified as $\mathrm{PCH}$ and which should not.

Genotype-phenotype correlations are most clear in TSEN54 (PCH2A and PCH4). Homozygosity for the p. A307S mutation in TSEN54 is strongly associated with a dragonfly configuration of the cerebellum, impaired swallowing and extrapyramidal movement disorders in infancy. In infants presenting with these symptoms and neuroradiological profile, prompt testing for this specific mutation is required. Patients compound heterozygous for the A307S mutation with a splice site or nonsense mutation on the other TSEN54 allele have a more severe phenotype characterized by congenital contractures and primary hypoventilation. In the majority of $\mathrm{PCH}$ patients, especially the milder ones and ones presenting with profound cerebral degeneration or other brain malformations, the diagnosis is less straightforward. Clinical, neuroradiological, metabolic and genetic data should be carefully evaluated and interpreted to get the correct diagnoses. It should not be overlooked that mutations in $\mathrm{PCH}$ related genes can also lead to milder phenotypes and might be revealed in adolescents or even young adults $[114,115]$. When interpreting possible disease causing variants identified with whole exome sequencing, Genematcher can be a very useful tool to identify similar patients. Genematcher is an online tool where clinicians or researchers can enter their gene of interest and will be connected to others with an interest in the same gene [116]. Targeted gene panels have been developed to facilitate fast genetic diagnosis in $\mathrm{PCH}$, but run the risk of being outdated soon because of the accelerated rate of new gene discovery.

The identification of novel genes resulted in new insights regarding the disease mechanism. Besides defects in RNA metabolism and protein synthesis, also other mechanisms like mitochondrial dysfunction (SLC25A46) and chromatin modelling (CHMP1A) are implied in $\mathrm{PCH}$. Despite the discovery of new pathways involved in $\mathrm{PCH}$, treatment is still symptomatic. $\mathrm{PCH}$ is a very rare disorder; in some subtypes only a few families are described. In addition, although clinical course is variable, the brain structure is already severely affect at birth in most children. These factors, together with the heterogeneous etiology in $\mathrm{PCH}$, complicate the development of a targeted therapeutic strategy.
Acknowledgements

We thank Bart Appelhof and Prof. Dr. Hanne Meijers-Heijboer for helpful discussions.

\section{Authors' contributions}

TVD wrote the manuscript. PGB, FB and BTPT critically reviewed the manuscript. All authors read and approved the manuscript.

Ethics approval and consent to participate

Not applicable.

\section{Consent for publication}

Consent for the publication of MRI images of the PCH patients was obtained via the referring medical doctors.

\section{Competing interests}

The authors declare that they have no competing interests.

\section{Publisher's Note}

Springer Nature remains neutral with regard to jurisdictional claims in published maps and institutional affiliations.

\section{Author details}

'Department of Clinical Genetics, Academic Medical Center, Amsterdam, The Netherlands. ${ }^{2}$ Department of Clinical Genetics, Leiden University Medical Center, Leiden, The Netherlands. ${ }^{3}$ Department of Pediatric Neurology, Academic Medical Center, Amsterdam, The Netherlands.

Received: 29 November 2017 Accepted: 16 May 2018

Published online: 15 June 2018

\section{References}

1. Brun R. Zur Kenntnis der Bildungsfehler des Kleinhirns. Epikritische Bemerkungen zur Entwicklungspathologie, Morphologie und Klinik der Umschriebenen Entwicklungshemmungen des Neozerebellums. Schweiz Arch Neurol Psychiatr. 1917;1:48-105.

2. Koster S, Case I. Two cases of hypoplasia pontoneocerebellaris. Acta Psychiatr Scand. 1926;1:47-83.

3. Bouman $\mathrm{KH}$. Atrophia olivo-pontocerebellaris. Ztschr f d ges Neurol u Psychiat. 1923:89:213-46.

4. Krause F. Über einen Bildungsfehler des Kleinhirns und einige faseranatomische Beziehungen des Organs. Zeitschrift der Gesammten Neurol und Psychiatr. 1928;119:788-815.

5. Norman RM. Cerebellar hypoplasia in Werdnig-Hoffmann disease. Arch Dis Child. 1960:36:96-101.

6. Goutieres F, Aicardi J, Farkas E. Anterior horn cell disease associated with pontocerebellar hypoplasia in infants. J Neurol Neurosurg Psychiatry. 1977; 40:370-8.

7. Kamoshita S, Takei Y, Miyao M, Yanagisawa M, Kobayashi S, Saito K. Pontocerebellar hypoplasia associated with infantile motor neuron disease (Norman's disease). Pediatr Pathol. 1999:10:133-42.

8. Chou SM, Gilbert EF, Chun RW, et al. Infantile olivopontocerebellar atrophy with spinal muscular atrophy (infantile OPCA + SMA). Clin Neuropathol. 1990;9(1):21-32.

9. Barth PG, Vrensen GFJM, Uylings HBM, Oorthuys JWE, Stam FC. Inherited syndrome of microcephaly, dyskinesia and pontocerebellar hypoplasia: a systemic atrophy with early onset. J Neurol Sci. 1990;97(1):25-42.

10. Peiffer J, Pfeiffer RA. Hypoplasia ponto-neocerebellaris. J Neurol. 1977;215: 241-51.

11. Barth PG. Pontocerebellar hypoplasias. An overview of a group of inherited neurodegenerative disorders with fetal onset. Brain Dev. 1993;15(6):411-22.

12. Eggens VR, Barth PG, J-MF N, et al. EXOSC3 mutations in pontocerebellar hypoplasia type 1: novel mutations and genotype-phenotype correlations. Orphanet J Rare Dis. 2014;9:23.

13. Rudnik-Schöneborn S, Senderek J, Jen JC, et al. Pontocerebellar hypoplasia type 1: clinical spectrum and relevance of EXOSC3 mutations. Neurology. 2013;80(5):438-46

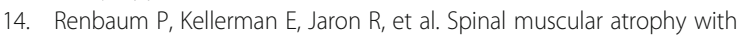
pontocerebellar hypoplasia is caused by a mutation in the VRK1 gene. Am J Hum Genet. 2009;85(2):281-9. 
15. Gonzaga-Jauregui $C$, Lotze $T$, Jamal L, et al. Mutations in VRK1 associated with complex motor and sensory axonal neuropathy plus microcephaly. JAMA Neurol. 2013;70(12):1491-8.

16. Stoll M, Teoh $\mathrm{H}$, Lee J, et al. Novel motor phenotypes in patients with VRK1 mutations without pontocerebellar hypoplasia. Neurology. 2016;87:65-70.

17. Wan J, Yourshaw M, Mamsa $H$, et al. Mutations in the RNA exosome component gene EXOSC3 cause pontocerebellar hypoplasia and spinal motor neuron degeneration. Nat Genet. 2012;44(6):704-8.

18. Boczonadi V, Müller JS, Pyle A, et al. EXOSC8 mutations alter mRNA metabolism and cause hypomyelination with spinal muscular atrophy and cerebellar hypoplasia. Nat Commun. 2014;5:4287.

19. Wan J, Steffen J, Yourshaw M, et al. Loss of function of SLC25A46 causes lethal congenital pontocerebellar hypoplasia. Brain. 2016;139(11):2877-90.

20. van Dijk T, Rudnik-Schöneborn S, Senderek J, et al. Pontocerebellar hypoplasia with spinal muscular atrophy (PCH1): identification of SLC25A46 mutations in the original Dutch PCH1 family. Brain. 2017;140:e46.

21. Budde BS, Namavar Y, Barth PG, et al. tRNA splicing endonuclease mutations cause pontocerebellar hypoplasia. Nat Genet. 2008;40(9):1113-8.

22. Namavar $Y$, Barth PG, Kasher PR, et al. Clinical, neuroradiological and genetic findings in pontocerebellar hypoplasia. Brain. 2011;134(1):143-56.

23. Namavar Y, Barth PG, Poll-The B, Baas F. Classification, diagnosis and potential mechanisms in pontocerebellar hypoplasia. Orphanet J Rare Dis. 2011;6(1):50.

24. Sánchez-Albisua I, Frölich S, Barth PG, Steinlin M, Krägeloh-Mann I. Natural course of pontocerebellar hypoplasia type 2A. Orphanet J Rare Dis. 2014;9(1):70.

25. Bierhals T, Korenke GC, Uyanik G, Kutsche K. Pontocerebellar hypoplasia type 2 and TSEN2: review of the literature and two novel mutations. Eur J Med Genet. 2013;56(6):325-30.

26. Breuss MW, Sultan T, James KN, et al. Autosomal-Recessive Mutations in the tRNA Splicing Endonuclease Subunit TSEN15 Cause Pontocerebellar Hypoplasia and Progressive Microcephaly. Am J Hum Genet. 2016;99(1):228-35.

27. Agamy O, Ben ZB, Lev D, et al. Mutations disrupting Selenocysteine formation cause progressive Cerebello-cerebral atrophy. Am J Hum Genet. 2010;87:538-44.

28. Pavlidou E, Salpietro V, Phadke R, et al. Pontocerebellar hypoplasia type $2 D$ and optic nerve atrophy further expand the spectrum associated with selenoprotein biosynthesis deficiency. Eur J Paediatr Neurol. 2016;20(3):483-8.

29. Iwama K, Sasaki M, Hirabayashi S, et al. Milder progressive cerebellar atrophy caused by biallelic SEPSECS mutations. J Hum Genet. 2016;61(6):527-31.

30. Feinstein $M$, Flusser $H$, Lerman-Sagie $T$, et al. VPS53 mutations cause progressive cerebello-cerebral atrophy type 2 (PCCA2). J Med Genet. 2014; 51(5):303-8.

31. Ahmed MY, Chioza BA, Rajab A, et al. Loss of PCLO function underlies pontocerebellar hypoplasia type III. Neurology. 2015;84(17):1745-50.

32. Rajab A, Mochida GH, Hill A, et al. A novel form of pontocerebellar hypoplasia maps to chromosome 7q11-21. Neurology. 2003;60(10):1664-7.

33. Durmaz B, Wollnik B, Cogulu O, et al. Pontocerebellar hypoplasia type III (CLAM): extended phenotype and novel molecular findings. J Neurol. 2009; 256(3):416-9.

34. Albrecht S, Schneider MC, Belmont J, Armstrong DL. Fatal infantile encephalopathy with olivopontocerebellar hypoplasia and micrencephaly report of three siblings. Acta Neuropathol. 1993;85(4):394-9.

35. Barth PG, Aronica E, Vries L, et al. Pontocerebellar hypoplasia type 2: a neuropathological update. Acta Neuropathol. 2007;114(4):373-86.

36. Rudaks LI, Moore L, Shand KL, Wilkinson C, Barnett CP. Novel TSEN54 mutation causing pontocerebellar hypoplasia type 4. Pediatr Neurol. 2011; 45(3):185-8

37. Patel MS, Becker LE, Toi A, Armstrong DL, Chitayat D. Severe, fetal-onset form of olivopontocerebellar hypoplasia in three sibs: PCH type 5? Am J Med Genet A. 2006;140(6):594-603.

38. Namavar $Y$, Chitayat $D$, Barth $P G$, et al. TSEN54 mutations cause pontocerebellar hypoplasia type 5. Eur J Hum Genet. 2011;19(6):724-6.

39. Cassandrini D, Cilio MR, Bianchi M, et al. Pontocerebellar hypoplasia type 6 caused by mutations in RARS2: definition of the clinical spectrum and molecular findings in five patients. J Inherit Metab Dis. 2013;36(1):43-53.

40. Edvardson S, Shaag A, Kolesnikova O, et al. Deleterious mutation in the mitochondrial Arginyl-transfer RNA Synthetase gene is associated with pontocerebellar hypoplasia. Am J Hum Genet. 2007;81(4):857-62.

41. Kastrissianakis K, Anand G, Quaghebeur G, et al. Subdural effusions and lack of early pontocerebellar hypoplasia in siblings with RARS2 mutations. Arch Dis Child. 2013;98(12):1004-7.
42. Lax NZ, Alston CL, Schon K, et al. Neuropathologic characterization of pontocerebellar hypoplasia type 6 associated with cardiomyopathy and Hydrops Fetalis and severe multisystem respiratory chain deficiency due to novel RARS2 mutations. J Neuropathol Exp Neurol. 2015;74(7):688-703.

43. Rankin J, Brown R, Dobyns WB, et al. Pontocerebellar hypoplasia type 6: a British case with PEHO-like features. Am J Med Genet Part A. 2010;152((8): 2079-84.

44. Alkhateeb AM, Aburahma SK, Habbab W, Thompson IR. Novel mutations in WWOX, RARS2, and C10orf2 genes in consanguineous Arab families with intellectual disability. Metab Brain Dis. 2016;31(4):901-7.

45. Lühl S, Bode H, Schlötzer W, et al. Novel homozygous RARS2 mutation in two siblings without pontocerebellar hypoplasia - further expansion of the phenotypic spectrum. Orphanet J Rare Dis. 2016;11(1):140.

46. Joseph J, Innes AM, Smith AC, et al. Neuropathologic features of pontocerebellar hypoplasia type 6. J Neuropathol Exp Neurol. 2014;73(11):1009-25.

47. Glamuzina E, Brown R, Hogarth $\mathrm{K}$, et al. Further delineation of pontocerebellar hypoplasia type 6 due to mutations in the gene encoding mitochondrial arginyl-tRNA synthetase, RARS2. J Inherit Metab Dis. 2012; 35(3):459-67.

48. Li Z, Schonberg N, Guidugli L, et al. A novel mutation in the promotor of RARS2 causes pontocerebellar hypoplasia in two siblings. J Hum Genet. 2015;60:363-9.

49. van Dijk $T$, van Ruissen $F$, Jaeger $B$, et al. RARS2 mutations: is pontocerebellar hypoplasia type 6 a mitochondrial encephalopathy?. JIMD Rep. 2017;33:87-92.

50. Mahbubul Huq AHM, Nigro MA. XY sex reversal and a nonprogressive neurologic disorder: a new syndrome? Pediatr Neurol. 2000;23(4):357-60.

51. Anderson C, Davies JH, Lamont L, Foulds N. Early pontocerebellar hypoplasia with vanishing testes: a new syndrome? Am J Med Genet Part A 2011:155(4):667-72

52. Lardelli RM, Schaffer AE, Eggens VRC, et al. Biallelic mutations in the $3^{\prime}$ exonuclease TOE1 cause pontocerebellar hypoplasia and uncover a role in snRNA processing. Nat Genet. 2017;49(3):457-64

53. Siriwardena K, Al-Maawali A, Guerin A, Blaser S, Chitayat D. XY sex reversal, pontocerebellar hypoplasia and intellectual disability: confirmation of a new syndrome. Am J Med Genet Part A. 2013:161(7):1714-7.

54. Mochida GH, Ganesh VS, de Michelena MI, et al. CHMP1A encodes an essential regulator of BMI1-INK4A in cerebellar development. Nat Genet. 2012:44(11):1260-4.

55. Akizu N, Cantagrel V, Schroth J, et al. AMPD2 regulates GTP synthesis and is mutated in a potentially treatable neurodegenerative brainstem disorder. Cell. 2013;154(3):505-17.

56. Marsh AP, Lukic V, Pope K, et al. Complete callosal agenesis, pontocerebellar hypoplasia, and axonal neuropathy due to AMPD2 loss. Neurol Genet. 2015; 1(2):e16.

57. Accogli A, lacomino $M$, Pinto $F$, et al. Novel AMPD2 mutation in pontocerebellar hypoplasia, dysmorphisms, and teeth abnormalities. Neurol Genet. 2017;3(5):e179.

58. Marsh APL, Yap P, Tan T, et al. A novel AMPD2 mutation outside the AMP deaminase domain causes pontocerebellar hypoplasia type 9. Am J Med Genet Part A. 2017:173(3):820-3.

59. Schaffer $A E$, Eggens VRC, Caglayan AO, et al. CLP1 founder mutation links tRNA splicing and maturation to cerebellar development and neurodegeneration. Cell. 2014;157(3):651-63.

60. Karaca E, Weitzer S, Pehlivan D, et al. Human CLP1 mutations alter tRNA biogenesis, affecting both peripheral and central nervous system function. Cell. 2014;157(3):636-50.

61. Marin-Valencia I, Gerondopoulos A, Zaki MS, et al. Homozygous mutations in TBC1D23 lead to a non-degenerative form of pontocerebellar hypoplasia. Am J Hum Genet. 2017;101(3):441-50

62. Ivanova EL, Mau-Them FT, Riazuddin S, et al. Homozygous truncating variants in TBC1D23 cause pontocerebellar hypoplasia and Alter cortical development. Am J Hum Genet. 2017;101(3):428-40.

63. Grosso S, Mostadini R, Cioni M, Galluzzi P, Morgese G, Balestri P. Pontocerebellar hypoplasia type 2: Further clinical characterization and evidence of positive response of dyskinesia to levodopa. J Neurol. 2002; 249(5):596-600

64. Barth PG, Blennow $\mathrm{G}$, Lenard $\mathrm{H}-\mathrm{G}$, et al. The syndrome of autosomal recessive pontocerebellar hypoplasia, microcephaly, and extrapyramidal dyskinesia (pontocerebellar hypoplasia type 2): compiled data from 10 pedigrees. Neurology. 1995;45(2):311-7. 
65. Barth $P G$, Ryan MM, Webster Rl, et al. Rhabdomyolysis in pontocerebellar hypoplasia type 2 (PCH-2). Neuromuscul Disord. 2008;18(1):52-8.

66. Zafeiriou DI, Ververi A, Tsitlakidou A, Anastasiou A, Vargiami E. Recurrent episodes of rhabdomyolysis in pontocerebellar hypoplasia type 2 . Neuromuscul Disord. 2013;23(2):116-9.

67. Poretti A, Boltshauser E, Doherty D. Cerebellar hypoplasia: differential diagnosis and diagnostic approach. Am J Med Genet Part C Semin Med Genet. 2014;166(2):211-26.

68. Feraco P, Mirabelli-Badenier M, Severino M, et al. The shrunken, bright cerebellum: a characteristic MRI finding in congenital disorders of glycosylation type 1a. Am J Neuroradiol. 2012;33(11):2062-7.

69. de Lonlay P, Seta N, Barrot S, et al. A broad spectrum of clinical presentations in congenital disorders of glycosylation I: a series of 26 cases. J Med Genet. 2001;38(1):14-9.

70. Monin M-L, Mignot C, De Lonlay P, et al. 29 French adult patients with PMM2-congenital disorder of glycosylation: outcome of the classical pediatric phenotype and depiction of a late-onset phenotype. Orphanet Rare Dis. 2014;9:207.

71. Grünewald $\mathrm{S}$. The clinical spectrum of phosphomannomutase 2 deficiency (CDG-la). Biochim Biophys Acta - Mol Basis Dis. 2009;1792(9):827-34.

72. Barone R, Fiumara A, Jaeken J. Congenital disorders of gycosylation with emphasis on cerebellar involvement. Semin Neurol. 2014;34:357-66.

73. Najm J, Horn D, Wimplinger I, et al. Mutations of CASK cause an X-linked brain malformation phenotype with microcephaly and hypoplasia of the brainstem and cerebellum. Nat Genet. 2008;40(9):1065-7.

74. Moog U, Bierhals T, Brand K, et al. Phenotypic and molecular insights into CASK-related disorders in males. Orphanet J Rare Dis. 2015;10(1):44.

75. Burglen L, Chantot-Bastaraud S, Garel C, et al. Spectrum of pontocerebellar hypoplasia in 13 girls and boys with CASK mutations: confirmation of a recognizable phenotype and first description of a male mosaic patient. Orphanet J Rare Dis. 2012;7(1):18.

76. Hackett A, Tarpey PS, Licata A, et al. CASK mutations are frequent in males and cause X-linked nystagmus and variable XLMR phenotypes. Eur J Hum Genet. 2009;18(5):544-52

77. Jaglin XH, Chelly J. Tubulin-related cortical dysgeneses: microtubule dysfunction underlying neuronal migration defects. Trends Genet. 2009; 25(12):555-66.

78. Fry AE, Cushion TD, Pilz DT. The genetics of lissencephaly. Am J Med Genet Part C Semin Med Genet. 2014;166(2):198-210.

79. Kumar RA, Pilz DT, Babatz TD, et al. TUBA1A mutations cause wide spectrum lissencephaly (smooth brain) and suggest that multiple neuronal migration pathways converge on alpha tubulins. Hum Mol Genet. 2010;19(14):2817-27.

80. Hong SE, Shugart YY, Huang DT, et al. Autosomal recessive lissencephaly with cerebellar hypoplasia is associated with human RELN mutations. Nat Genet. 2000;26(1):93-6.

81. Valence S, Garel C, Barth M, et al. RELN and VLDLR mutations underlie two distinguishable clinico-radiological phenotypes. Clin Genet. 2016; 90(6):545-9.

82. Boycott KM, Flavelle S, Bureau A, et al. Homozygous deletion of the very low density lipoprotein receptor gene causes autosomal recessive cerebellar hypoplasia with cerebral gyral simplification. Am J Hum Genet. 2005;77(3): 477-83

83. Schorling DC, Kirschner J, Bönnemann CG. Congenital muscular dystrophies and congenital myopathies: an overview and update. Neuropediatrics. 2017; 48:247-61.

84. Poretti A, Klein A, Boltshauser E. Cerebellar cysts and neuroimaging in congenital muscular dystrophys. In: Boltshauser E and Schmahmann, editors. Cerebellar disorders in children. Mac Keith Press; 2012. p.177-183.

85. Clement E, Mercuri E, Godfrey C, et al. Brain involvement in muscular dystrophies with defective dystroglycan glycosylation. Ann Neurol. 2008; 64(5):573-82.

86. Sznajer $Y$, Baumann C, David A, et al. Further delineation of the congenital form of $X$-linked dyskeratosis congenita (Hoyeraal-Hreidarsson syndrome). Eur J Pediatr. 2003;162(12):863-7.

87. Knight SW, Heiss NS, Vulliamy TJ, et al. Unexplained aplastic anaemia, immunodeficiency, and cerebellar hypoplasia (Hoyeraal-Hreidarsson syndrome) due to mutations in the dyskeratosis congenita gene, DKC1. Br J Haematol. 1999:107(2):335-9.

88. Storey E. Genetic cerebellar ataxias. Semin Neurol. 2014;34(3):280-92.

89. Poretti A, Wolf NI, Boltshauser E. Differential diagnosis of cerebellar atrophy in childhood: an update. Neuropediatrics. 2015;46(6):359-70.
90. Singh A, Faruq M, Mukerji M, Dwivedi MK, Pruthi S, Kapoor S. Infantile onset spinocerebellar ataxia 2 (SCA2): a clinical report with review of previous cases. J Child Neurol. 2014;29(1):139-44.

91. Donis KC, Mattos EP, Silva AA, et al. Infantile spinocerebellar ataxia type 7: case report and a review of the literature. J Neurol Sci. 2015;354(12):118-21.

92. van Dijk T, Barth P, Reneman L, Appelhof B, Baas F, Poll-The BT. A de novo missense mutation in the inositol 1,4,5-triphosphate receptor type 1 gene causing severe pontine and cerebellar hypoplasia: expanding the phenotype of ITPR1-related spinocerebellar ataxia's. Am J Med Genet Part A. 2017;173(1):207-12

93. Desai $R$, Frazier AE, Durigon $R$, et al. ATAD3 gene cluster deletions cause cerebellar dysfunction associated with altered mitochondrial DNA and cholesterol metabolism. Brain. 2017;140(6):1595-610.

94. Peeters-Scholte CMPCD, Adama van Scheltema PN, Klumper FJCM, et al. Genotype-phenotype correlation in ATAD3A deletions: not just of scientific relevance. Brain. 2017;140(11):e66.

95. Messerschmidt A, Brugger PC, Boltshauser E, et al. Disruption of cerebellar development: potential complication of extreme prematurity. Am J Neuroradiol. 2005;26(7):1659-67.

96. Volpe JJ. Cerebellum of the premature infant: rapidly developing, vulnerable, clinically important. J Child Neurol. 2009;24(9):1085.

97. Brossard-Racine M, du Plessis AJ, Limperopoulos C. Developmental cerebellar cognitive affective syndrome in ex-preterm survivors following cerebellar injury. Cerebellum. 2015;14(2):151-64.

98. Fasken MB, Losh JS, Leung SW, et al. Insight into the RNA exosome complex through modeling pontocerebellar hypoplasia type $1 \mathrm{~b}$ disease mutations in yeast. Genetics. 2017;205(1):221-37.

99. Wichtowska D, Turowski TW, Boguta M. An interplay between transcription, processing, and degradation determines tRNA levels in yeast. Wiley Interdiscip Rev RNA. 2013;4(6):709-22.

100. Kadaba S, Krueger A, Trice T, Krecic AM, Hinnebusch AG, Anderson J. Nuclear surveillance and degradation of hypomodified initiator tRNA Met in S. cerevisiae. Genes Dev. 2004;18(11):1227-40.

101. Gillespie A, Gabunilas J, Jen JC, Chanfreau GF. Mutations of EXOSC3/Rrp40p associated with neurological diseases impact ribosomal RNA processing functions of the exosome in S. cerevisiae. RNA. 2017;23(4):466-72.

102. Palioura S, Sherrer RL, Steitz TA, Söll D, Simonović M. The human SepSecStRNASec complex reveals the mechanism of Selenocysteine formation. Science. 2009:325(6):321-6.

103. wing FK, Li Y, Wang W, et al. Whole-genome screening identifies proteins localized to distinct nuclear bodies. J Cell Biol. 2013;203(1):149-64.

104. Valbuena A, Sanz-García M, López-Sánchez I, Vega FM, Lazo PA. Roles of VRK1 as a new player in the control of biological processes required for cell division. Cell Signal. 2011;23(8):1267-72.

105. Cantarero L, Sanz-García M, Vinograd-Byk H, Renbaum P, Levy-Lahad E, Lazo PA. VRK1 regulates Cajal body dynamics and protects coilin from proteasomal degradation in cell cycle. Sci Rep. 2015;5:10543.

106. Vinograd-byk H, Sapir T, Cantarero L, et al. The spinal muscular atrophy with pontocerebellar hypoplasia gene VRK1 regulates neuronal migration through an amyloid- precursor protein-dependent mechanism. J Neurosci. 2015;35(3):936-42

107. Kononenko N, Pechstein A, Haucke V. Synaptic requiem: a duet for piccolo and bassoon. EMBO J. 2013;32(7):920-2.

108. Waites $C L$, Leal-Ortiz SA, Okerlund N, et al. Bassoon and piccolo maintain synapse integrity by regulating protein ubiquitination and degradation. EMBO J. 2013;32(7):954-69.

109. Koning IV, Dudink J, Groenenberg IAL, Willemsen SP, Reiss IKM, SteegersTheunissen RPM. Prenatal cerebellar growth trajectories and the impact of periconceptional maternal and fetal factors. Hum Reprod. 2017;32(6):1230-7.

110. Mathijssen IB, Henneman L, van Eeten-Nijman JMC, et al. Targeted carrier screening for four recessive disorders: high detection rate within a founder population. Eur J Med Genet. 2015;58(3):123-8.

111. Steinlin $M$, Klein A, Haas-Lude $K$, et al. Pontocerebellar hypoplasia type 2: variability in clinical and imaging findings. Eur J Paediatr Neurol. 2007;11(3):146-52.

112. Graham JM, Spencer AH, Grinberg I, et al. Molecular and neuroimaging findings in pontocerebellar hypoplasia type $2(\mathrm{PCH} 2)$ : is prenatal diagnosis possible? Am J Med Genet Part A. 2010;152((9):2268-76.

113. Goasdoué $P$, Rodriguez D, Moutard ML, Robain O, Lalande G, Adamsbaum C. Pontoneocerebellar hypoplasia: definition of MR features. Pediatr Radiol. 2001;31(9):613-8. 
114. Halevy A, Lerer I, Cohen R, et al. Novel EXOSC3 mutation causes complicated hereditary spastic paraplegia. J Neurol. 2014;261:2165-9.

115. Van Dijk T, Vermeij J-D, van Koningsbruggen S, Lakeman P, Baas F, Poll-The BT. A SEPSECS mutation $n$ a 23-year old woman with microcephaly and progressive cerebellar ataxia. J Inherit Metab Dis. 2018. doi: https://doi.org/ 10.1007/s10545-018-0151-x.

116. Sobreira N, Schiettecatte F, Valle D, Hamosh A. GeneMatcher: a matching tool for connecting investigators with an interest in the same gene. Hum Mutat. 2015;36(10):928-30.

Ready to submit your research? Choose BMC and benefit from:

- fast, convenient online submission

- thorough peer review by experienced researchers in your field

- rapid publication on acceptance

- support for research data, including large and complex data types

- gold Open Access which fosters wider collaboration and increased citations

- maximum visibility for your research: over $100 \mathrm{M}$ website views per year 